\title{
Direito Ao Desenvolvimento: Desafios Econômicos, Jurídicos E Éticos Nos Tempos De Coronavírus (Covid-19)
}

\author{
Daniel Jacomelli Hudler* \\ Universidade Nove de Julho, Programa de Pós-Graduação em Direito, São Paulo-SP, \\ Brasil. \\ https://orcid.org/oooo-0oo2-1171-4063 \\ Marcelo Benacchio** \\ Universidade Nove de Julho, Programa de Pós-Graduação em Direito, São Paulo-SP, \\ Brasil. \\ https://orcid.org/oooo-0003-1348-1352
}

Resumo: Objetiva-se uma compreensão sobre desafios econômicos, jurídicos e éticos para o direito ao desenvolvimento no cenário de crises globais desencadeadas pela pandemia do novo coronavírus (COVID-19). O presente artigo utiliza-se do método hipotético-dedutivo, com auxílio de pesquisa bibliográfica. A primeira parte destina-se à identificação das linhas de pensamento econômico incorporadas ao discurso jurídico no final do século XX (neoliberal, sustentável e humana) e enquadramento enquanto direito humano fundamental no contexto de uma sociedade informacional de economia global; na segunda, descrevem-se os desafios econômicos e jurídicos aos países em desenvolvimento e o aprofundamento da crise econômico-financeira causada pela pandemia; na terceira, apresentam-se reflexões éticas sobre a relação entre Estados e a integração dos demais atores sociais no enfrentamento da pandemia. Conclui-se que a comunidade internacional, apesar das dificuldades apresentadas, caminha para uma compreensão do Estado, da empresa, e da sociedade civil enquanto coparticipantes do processo de desenvolvimento, a partir da multilateralidade e responsabilidade compartilhada propostas em compromissos globais acompanhados de instrumentos mais precisos de aferição do desenvolvimento, da internalização desses compromissos a partir de esforços comuns, bem como da importância desta realidade como pressuposto à elaboração de novos marcos regulatórios internos.

Palavras-chave: Direito ao desenvolvimento. Desenvolvimento humano e sustentável. Direitos Humanos. Empresas transnacionais. Coronavirus (COVID-19).

\footnotetext{
* Mestrando em Direito pela UNINOVE. Bolsista PROSUP/CAPES. E-mail: djhudler@gmail.com

** Doutor em Direito pela Pontifícia Universidade Católica de São Paulo (PUC/SP). Professor permanente do Mestrado em Direito e da Graduação da Universidade Nove de Julho (UNINOVE-SP). Professor Titular de Direito Civil da Faculdade de Direito de São Bernardo do Campo. Juiz de Direito em São Paulo. E-mail: benamarcelo@gmail.com
}

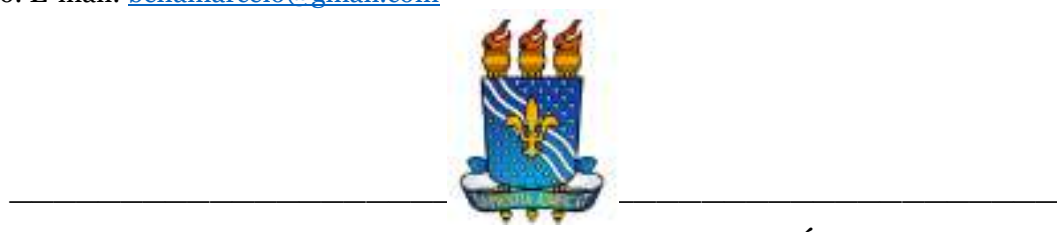

UNIVERSIDADE FEDERAL DA PARAÍBA

Programa de Pós-Graduação em Ciências Jurídicas

DOI: https://doi.org/10.22478/ufpb.1678-2593.2020v19n42.51843 


\title{
Direito Ao Desenvolvimento: Desafios Econômicos, Jurídicos E Éticos Nos Tempos De Coronavírus (Covid-19)
}

\author{
Daniel Jacomelli Hudler ${ }^{1}$
}

\section{Marcelo Benacchio}

\section{INTRODUÇÃO}

Nas últimas décadas, o desenvolvimento assumiu uma feição qualitativa no sentido de promoção do bem-estar a todas as pessoas. No atual contexto de crises globais engatilhadas pela pandemia do coronavírus (COVID-19), os desafios em torno deste objetivo evidenciam mais uma vez a difícil equalização entre Estados desenvolvidos e em desenvolvimento.

Apesar de avanços econômicos e sociais das últimas décadas, ampliou-se o abismo entre pessoas que possuem acesso a bens e serviços e aquelas que são desprovidas do essencial. Exemplo atual disso está no enfrentamento da pandemia por meio das medidas de distanciamento social: há pessoas que possuem renda e empregos estáveis, que desfrutam de bens e serviços diretamente em casa, enquanto outra porção considerável, que depende do funcionamento do mercado informal, encara tais medidas com maior exposição ao contágio e grande vulnerabilidade.

Por esses motivos, reacende-se o debate sobre a implementação de um "direito ao desenvolvimento" e a possibilidade de criação de um marco regulatório específico para a temática, a partir da reflexão sobre

\footnotetext{
${ }^{1} \mathrm{O}$ presente trabalho foi realizado com apoio da Coordenação de Aperfeiçoamento de Pessoal de Nível Superior - Brasil (CAPES) - Bolsa PROSUP.
} 
pontos econômicos, jurídicos e éticos relevantes e atuais. Para além da dificuldade de concentração e regulação das diversas áreas relacionadas ao desenvolvimento em âmbito local, a discussão assume a pretensão de redução de disparidades também em um nível global e, consequentemente, enfrenta uma diversidade de desafios, cuja solução poderá estar além das disponibilidades encontradas no Estado-nação moderno. O objetivo, portanto, é a compreensão destes desafios no atual contexto de pandemia.

Justifica-se, assim, a apresentação dos seguintes questionamentos: i) o desenvolvimento limita-se às possibilidades econômico-financeiras de cada Estado ou constitui um direito humano fundamental a ser considerado em um contexto global?; ii) quais os desafios econômicos e jurídicos para o direito ao desenvolvimento e como a COVID-19 aprofundou a crise econômico-financeira nos países em desenvolvimento?; iii) Os Estados são os únicos atores sociais responsáveis pelo combate direto à pandemia e pela amenização das perdas econômicas, sociais e de vidas humanas?

Na tentativa de respondê-las, o presente estudo utiliza-se do método hipotético-dedutivo, com auxílio de uma pesquisa bibliográfica, e divide-se em três partes: a primeira apresenta o contexto de uma sociedade informacional de economia global consolidada ao final do século XX, no qual algumas compreensões econômicas foram incorporadas ao pensamento jurídico atual, classificadas didaticamente como linha de desenvolvimento neoliberal, desenvolvimento sustentável e desenvolvimento humano; a segunda parte centraliza-se na descrição dos desafios econômicos e jurídicos, no cenário de aprofundamento da crise econômicofinanceiro dos países em desenvolvimento em razão da COVID-19; e, por fim, a terceira apresenta reflexões éticas relacionadas ao enfrentamento da pandemia, no contexto de busca da humanidade por um modelo de gerenciamento de crises globais. 


\section{DESENVOLVIMENTO NA SOCIEDADE INFORMACIONAL DE ECONOMIA GLOBAL: UMA QUESTÃO ECONÔMICA DE CADA ESTADO OU UM DIREITO HUMANO FUNDAMENTAL?}

No intuito de compreender se o desenvolvimento está restrito às possibilidades econômicas de cada Estado ou se este se revela como um verdadeiro direito humano fundamental, indispensável uma leitura a partir do contexto de uma sociedade informacional de economia global, marcado sobretudo pelos fenômenos da globalização, da formação dos Estados-nação modernos e de novas formas de se pensar a economia.

O Estado-nação se tornou verdadeiramente global somente no final do século XX, com o fim dos impérios e a disseminação de novas formas multilaterais de coordenação e cooperação internacionais ou "sistema emergente de governança global" (HELD; MCGREW, 2001, p. 24-36). Este modelo de gestão de crises globais possui como pilares o Estado Democrático de Direito e a economia de mercado. Para sua garantia, elaborou-se um sistema financeiro internacional e um sistema internacional de proteção de Direitos Humanos. O primeiro estruturou-se a partir dos acordos de Bretton Woods, de 1944, sob a premissa keynesiana de que os mercados não funcionam bem sem que haja uma coordenação a nível global, e objetivou primeiro a restauração da economia europeia para posteriormente fomentar o desenvolvimento das economias periféricas (STIGLITZ, 2017, p.103119).

$\mathrm{Na}$ atualidade, o Estado-nação ainda é palco da legitimação de decisões democráticas. No entanto, a amplitude do seu poder decisório foi mitigada em face da pressão política externa e dos compromissos internacionais cada vez mais complexos dos governos. Como sintetizam Held e McGrew (2001, p.31): "o Estado transformou-se numa arena fragmentada de formulação de decisões políticas, 
Direito Ao Desenvolvimento: Desafios Econômicos, Jurídicos E Éticos Nos...

permeada por redes transnacionais (governamentais e não governamentais) e por órgãos e forças internos".

Embora não se cogite o fim do Estado-nação, nítido que houve o seu enfraquecimento, seja pela diminuição da máquina estatal como resultado da adoção de "políticas neoliberais"2, seja pelo surgimento de blocos econômicos (POMPEU, 2012). Assim, é no bojo deste arranjo internacional que floresceu a sociedade informacional de economia global, caracterizada sobretudo pela superação das restrições espaço-temporais e intensificação de interações transnacionais, inclusive relacionadas ao fluxo de capital financeiro e à dinâmica de acesso e trocas desiguais de fatores de produção, onde a empresa privada progressivamente substituiu o Estado como ator principal (FARIA, 2002, p. 61-62).

A partir deste modelo, no qual há um descolamento do centro de decisões políticas em relação às decisões econômico-financeiras impulsionado pela autorregulação das relações privadas promovida pelos atores não governamentais e empresas transnacionais, que também influenciam o direito interno (BRASIL; OLIVEIRA; TRINDADE, 2018, p.5-15) - é que a discussão sobre a economia se eleva a um patamar diferenciado e os estudos sobre desenvolvimento em sua dimensão econômica ganham maior relevância.

Neste passo, a própria noção (ou noções) sobre o que é desenvolvimento e como implementá-lo passa a ser considerada também sob essa ótica de economia de mercado global permeada por relações transnacionais. E, neste contexto, possível a identificação de três linhas principais.

A primeira, genericamente apresentada na literatura crítica como linha de pensamento neoliberal, ganhou notoriedade a partir de autores como Friedrich Hayek, Ludwig Von Mises e Milton Friedman,

${ }^{2}$ Dentre as quais destacam-se: a reorientação das despesas públicas; a reforma tributária; a liberalização financeira e do mercado; as taxas de câmbio unificadas e competitivas; a abertura irrestrita a investimento estrangeiro direto; a privatização de empresas estatais; a desregulamentação de setores econômicos; redução de gastos estatais, inclusive com redução de programas sociais e da sua estrutura administrativa. 
e nas décadas de 1970 e 1980, pelo conjunto de medidas de austeridade fiscal e "desregulamentação" macroeconômicas 3 sugeridas aos Estados em desenvolvimento, endossadas pelos economistas do Banco Mundial, FMI e Departamento do Tesouro norte-americano, reunidas e nomeadas pelo economista John Williamson de "Consenso de Washington" (RODRIK, 2006).

O cerne filosófico desta linha centraliza-se no indivíduo e tem como traço comum a invocação de pensadores liberais do século XVIII, a exemplo de Adam Smith, David Ricardo e John Locke. Aduzse que o ser humano naturalmente realizaria escolhas racionais em prol da maximização do seu proveito. Neste sentido, rememora-se o pensamento de Adam Smith (1981, p.23) em que a riqueza das nações, em última análise, é impulsionada por um sentimento egoístico de cada indivíduo4. Nesta ótica, a potencialização dos benefícios à comunidade se daria de forma indireta e dependeria de uma drástica redução da intervenção estatal no âmbito econômico, possibilitando maior produtividade e oferta de bens e serviços pelo livre mercado.

Por outro lado, não se ignora a visão crítica, que entende esta linha como doutrina teórico-prática de justificação política que tende a absolutizar o mercado até convertê-lo em meio, método e fim do comportamento humano, de modo a submeter a vida das pessoas, o comportamento da sociedade e a política dos governos ao mercado (WOLKMER; WOLKMER, 2005, p.61-71) ou como uma forma de explicar a atuação do ser humano a partir de uma racionalidade suspostamente deduzível pela formalidade do raciocínio lógico e de um cálculo do bem-estar social segundo uma somatória de maximização utilitarista do bem-estar individual, que não corresponde à realidade (BRANCO, 2012, p.13).

A linha do desenvolvimento sustentável defende a necessidade de se atingir um equilíbrio ecológico, social e econômico, e ganhou

4 No original: "it's not from the benevolence of the butcher, the brewer, or the baker, that we expect our dinner, but from their regard to their own interest" 4 . 
espaço nos debates internacionais, especialmente no âmbito da ONU5. Neste ponto, vale enaltecer a obra precursora de Ignacy Sachs, influenciado tanto pelos estudos de Celso Furtado - segundo os quais as economias periféricas não poderiam atingir o crescimento econômico das economias centrais em razão das próprias limitações do sistema capitalista vigente (FURTADO, 1974, p.68-76) - quanto pelos estudos cepalianos no sentido de que uma possível superação do subdesenvolvimento se realizaria por meio de um processo de rápida industrialização (ou pela substituição de importações), planejado e conduzido pelo Estado, conjugado com a reforma agrária, expansão do mercado interno, política de pleno emprego, e de fortalecimento da agricultura familiar (SACHS, 2001, p.45-52).

A linha do desenvolvimento humano, por sua vez, ganhou seus contornos a partir das obras do indiano Amartya Kumar Sen e do paquistanês Mahbub ul Haq. A premissa filosófica é de que o desenvolvimento não pode estar dissociado de um processo contínuo de expansão das liberdades reais, garantido a partir da eliminação de limitadores das escolhas humanas, como a pobreza extrema, fome, tirania (falta de instituições democráticas e de participação popular na política), carência de oportunidades e a destituição social sistemática (SEN, 2013, p. 16-20) e de que o sucesso das políticas públicas de desenvolvimento deve ser mensurado não apenas pelo crescimento econômico e aprimoramento técnico dos processos produtivos, mas sobretudo pela melhora na qualidade de vida das pessoas (HAQ, 1995, p.15-17).

Sob prisma jurídico, esses pensamentos também foram incorporados, especialmente por autores ligados ao sistema internacional de direitos humanos. Neste sentido, destaca-se a

\footnotetext{
5 A partir da Conferência de Estocolmo de 1972, da apresentação do Relatório "Nosso Futuro Comum" (Relatório Brundtland) em 1987, e da Conferência das Nações Unidas sobre o Meio Ambiente e Desenvolvimento de 1992 (RIO-92), bem como os demais acontecimentos de relevância: a concepção do Triple bottom line por John Elkington em 1999 (e o seu repensar crítico em 2018), Conferência mundial "Rio + dez" que instituiu o "Business Action for Sustainable Development" em 2002, a apresentação do documentário "An inconveniente truth" de Davis Guggenheim sobre militância política americana de $\mathrm{Al} \mathrm{Gore,} \mathrm{dentre} \mathrm{outros} \mathrm{fatos} \mathrm{relevantes.}$
} 
contribuição de Kéba M’Baye que, a partir dos estudos de Karel Vasak sobre as "gerações" de direitos humanos, empregou o termo em conferência inaugural do Curso de Direitos Humanos do Instituto Internacional de Direitos do Homem de Estrasburgo (1972), publicada com o título de "O direito ao desenvolvimento como um direito do Homem" (BONAVIDES, 2004, p.569-570; ANJOS FILHO, 2009, p. 70-92; M'BAYE, 1989, p.38). O autor esclarece que direito ao desenvolvimento seria um

[...] poder ou uma prerrogativa, e diz respeito ao homem e à coletividade; toda a população deve participar livremente do desenvolvimento e aproveitar a estrita igualdade e justiça; o direito ao desenvolvimento postula o exercício dos direitos humanos e das liberdades fundamentais; a escolha do modelo de desenvolvimento deverá ser livre; deverá ser exercido nacional e internacionalmente; pressupõe cooperação em bases eqüitativas; deverá respeitar o princípio do direito dos povos à autodeterminação (M’BAYE, 1989, p. 69, tradução nossa $\left.{ }^{6}\right)$.

Em que pese inexista um tratado internacional específico, possível perceber o caminho para seu reconhecimento jurídico a partir de diversas conferências e documentos internacionais7. Do ponto de

${ }^{6}$ No original: "En cernant de plus près les élements constitutifs du droit au développement, il ne sera pas impossible de trouver une definition. Notons que: le droit au développement est um pouvoir ou une prérogative;il concerne à la fois l'homme et tous les hommes pris collectivement; l'ensemble de la population doit participer librement au développement et em profiter sur une stricte egalité et em toute justice; le droit au développement postule l'exercice des droit de l'homme et des libertés fondamentales; le choix du modele de développement doit être libre; le droit au droit au développement s'exerce tanta u plan national qu'international; il suppose la coopération sur une base équitable; il doit respecter le príncipe du droit des peuples à disposer d'eux-mêmes".

7 Neste sentido, por exemplo: a Carta das Nações Unidas de 1945, enunciava a existência de direitos sociais, econômicos e culturais, tendentes ao progresso da qualidade e vida do ser humano, autodeterminação dos povos, e o desenvolvimento econômico e social (Preambulo, art. $1^{\circ}$ e $55^{\circ}$ ); Declaração Universal dos Direitos Humanos de 1948, que no art. XXII estabelece a promoção direitos econômicos, sociais, culturais "de acordo com os recursos de cada Estado" e o desenvolvimento da personalidade; as Resoluções 1710 (XVI) e 1.715(XV) de 1961, que evidenciam o caráter global do subdesenvolvimento e a necessidade de se desenvolver a solidariedade internacional e o desenvolvimento dos países em processo de descolonização; a Conferência das Nações Unidas Sobre Comércio e Desenvolvimento (UNCTAD) de 1964, em que houve a menção no discurso de abertura para que o direito de todos os povos ao desenvolvimento ser reconhecido e respeitado; o próprio Pacto Internacional Sobre Direitos Econômicos, Sociais e Culturais de 1966, no art. 11, que menciona a necessidade de se garantir um padrão 
vista conceitual, destaca-se a Declaração sobre Direito ao

Desenvolvimento, de 1986, que apresenta já em seu artigo primeiro o desenvolvimento enquanto um direito humano inalienável por meio do qual todas as pessoas deverão participar e desfrutar do processo econômico, social, cultural e político com vistas ao constante incremento do bem-estar de todos (UN, 1986).

Com efeito, a cristalização do direito ao desenvolvimento enquanto direito - e mais propriamente como um direito humano fundamental - se deve em grande parte àquela perspectiva globalista da ONU, que teve como propósito a expansão dos direitos humanos preexistentes, à luz da unidade de concepção e indivisibilidade, elevando-os a um lugar central na agenda internacional do século XXI (TRINDADE, 1999, p.261-329).

Essa tendência é seguida também por autores brasileiros: Paulo Bonavides (2004, p. 569-570) entende o desenvolvimento como um

de vida adequado, alimentação, vestimenta, moradia e melhoria contínua das condições de vida; a II Conferência das Nações Unidas Sobre Comércio e Desenvolvimento (UNCTAD) de 1968 também apresenta o debate sobre a redução desigualdades entre Estados por meio da adoção de mecanismos aduaneiros; a Declaração sobre progresso social e desenvolvimento de 1969 , que nos arts. $1^{\mathrm{o}}, 2^{\mathrm{o}}$ , $9^{\circ}$ preveem a eliminação da desigualdade, exploração de pessoas e do colonialismo, em que o desenvolvimento é preocupação da comunidade internacional e necessita de ação internacional coordenada para melhoria dos povos; a Resolução $n$. $2.626(X X V)$ de 1970 , que estabelece o próprio conceito de desenvolvimento como incremento sustentável ao bem estar do indivíduo e da coletividade; Declaração sobre o estabelecimento de uma nova ordem econômica internacional (Res. 3.201) de 1974; a Carta de Direitos e Deveres Econômicos dos Estados de 1974, que reforça a necessidade de se estabelecer uma responsabilização dos Estados em face do descumprimento dos direitos econômicos; a Resolução $\mathrm{n}^{0} 3.362$ sobre Desenvolvimento e Cooperação Econômica de 1975; a Resolução $\mathrm{n}^{\circ} 34 / 138$ sobre Negociações Globais relativas à Cooperação Econômica Internacional para o Desenvolvimento de 1979; a Resolução $n^{o} \quad 41 / 73$ sobre desenvolvimento progressivo dos princípios e normas de Direito Internacional relativos à Nova Ordem Econômica Internacional de 1986; e, por fim, a Declaração das Nações Unidas Sobre Direito ao Desenvolvimento (Res. 41/128) de 1986, com destaque para sua votação, no sentido de que o único voto contrário foi dos Estados Unidos da América e com abstenções por parte de diversos países desenvolvidos, como Dinamarca, Alemanha, Reino Unido, Finlândia, Islândia, Suécia, Japão e Israel; a Consulta Global sobre Direito ao Desenvolvimento como um Direito humano de 1990 , que se destaca pelo estímulo à participação e pela defesa das instituições democráticas; a Declaração sobre meio ambiente e desenvolvimento - Declaração do Rio 92 - de 1992; a Conferência Mundial de Direitos Humanos de Viena de 1993, que resultou na Declaração e programa de Ação de Viena, pela qual se consagra não apenas o direito ao desenvolvimento, mas o adota como um direito humano universal, indivisível, interdependente e inter-relacionado, conforme seu item 10. 
direito fundamental de terceira geração; Flávia Piovesan (2010) reconhece enquanto direito humano fundamental; Ingo Wolfgang Sarlet e Tiago Fensterseifer (2014, p.127), enquadram como princípio do desenvolvimento sustentável (art. 170, inc. VI, da CF), o qual estabelece um dever fundamental ao Estado e à sociedade como contraponto ao direito de propriedade privada e livre iniciativa (caput e inc. II do art. 170, da CF); Vladmir Oliveira da Silveira e Samyra Sanches (2013, p.125) defendem que não se trata de um "novo direito", mas de uma dimensão atual dos direitos humanos econômicos.

Desta forma, no contexto de uma sociedade informacional de economia global permeada por relações transnacionais, o desenvolvimento deixa de ser uma questão exclusiva de cada Estado, e passa a ter relevância em âmbito global, enquanto um direito humano fundamental, que deve ser considerado por todos os atores sociais e não somente pelo Estado, em benefício direto das pessoas e de suas comunidades.

\section{DESAFIOS PARA O DESENVOLVIMENTO: LIMITAÇÕES ECONÔMICAS E JURÍDICAS EM TEMPOS DE COVID-19}

Após a compreensão sobre o que seria o desenvolvimento e o porquê considerá-lo como um direito humano, pergunta-se: quais os desafios econômicos e jurídicos para o desenvolvimento e como a COVID-19 aprofundou a(s) crise(s) nos países em desenvolvimento?

De forma preliminar, destacam-se aspectos comuns desses países: 1 - sob prisma econômico, há dependência do modelo de exportação de commodities e, em certos casos, do turismo; 2 - sob ponto de vista financeiro, há fragilidade de seus mercados, os quais são mais suscetíveis à volatilidade dos fluxos de capitais e às oscilações dos preços mundiais, de modo a afastar investimentos mais duradouros considerados de maior risco (OECD, 2020, p.2-4); 3 - sob enfoque fiscal, há dificuldade de controle da dívida pública e uso recorrente de 
financiamentos externos para promoção do desenvolvimento local (UNECA, 2020, p.5-15; ECLAC, 2020, p.2-10).

Apesar da estratégia de equilíbrio das finanças públicas por meio das exportações ter apresentado resultados inicialmente positivos, este ciclo já apresentava sinais de decadência por diversas mudanças no cenário econômico global (WORLD BANK, 2020a, p. 1012). A quebra da cadeia de suprimentos pelas medidas recentes de confinamento social apenas acelerou este processo, na medida em que diversos países localizados na América Latina e África já apresentavam baixo crescimento econômico pelas tendências de redução da demanda global e depreciação no preço de commodities (WORLD BANK, 2020b, p.7-13; IMF, 2020, p.2-6), inclusive como reflexo da redução do ritmo de importações de potências econômicas como Estados Unidos, China e Europa (ECLAC, 2020, p.7-9).

Deste processo, nota-se que as medidas de confinamento social e de enfrentamento da crise sanitária não apenas reduziram a atividade econômica global, mas estimularam uma redução de consumo energético geral, resultando também na redução do preço do petróleo e aumento do custo de transportes pelas dificuldades logísticas ${ }^{8}$, o que prejudicou economias de países em desenvolvimento que dependiam dessas relações para manutenção de seu frágil equilíbrio fiscal, gerando indicadores de mercado piores do que da crise de 2008 (WORLD BANK, 2020b, p.1-12).

De fato, os riscos deste modelo econômico preexistente apenas se somaram àqueles já reconhecidos pela CEPAL no ano anterior, relacionados à baixa produtividade e ao risco ambiental9 (ECLAC,

\footnotetext{
${ }^{8}$ Dentre as quais, destacam-se: a) adoção de medidas de higienização; b) adoção de procedimentos administrativos mais rigorosos para evitar a aglomeração e dificultar a circulação de pessoas; c) redução de pessoal operacional, d) aumento do preço de cargas de itens médicos, alimentícios e de produtos de higienização, em razão do aumento da procura por estes itens.

9 baixa produtividade: em razão da concentração de investimentos no setor extrativista e do baixo investimento em tecnologia, há uma redução da participação do país no seu valor agregado no âmbito da cadeia global: isto é, o retorno dos investimentos é comparativamente inferior ao dos países desenvolvidos, os quais trabalham com os últimos estágios de produção e prestação de serviços. Este modelo econômico também se associa à armadilha ambiental: muito embora seja 
2019, p.95-116). Neste sentido também o estudo pelo economista britânico Paul Collier (2007, p.38-40), que já alertava para a ausência de diversificação econômica dos países africanos, os quais não aproveitaram seu potencial para expansão do fornecimento de produtos e serviços e, consequentemente, estariam prejudicados em seu desenvolvimento econômico e social a longo prazo, porque suscetíveis à depreciação do preço das commodities e a possibilidade de não integração de suas economias.

Sob o aspecto fiscal, vale ressaltar a complexidade da situação: para financiamento do desenvolvimento e do setor produtivo, aumentou-se o endividamento público (por meio do financiamento direto ou de incentivos fiscais) e também do próprio setor privado (débitos não financiados pelo Estado, com assunção de maiores riscos ao empresariado). Entretanto, a possibilidade de pagamento desses débitos tornou-se mais difícil, seja em razão das condições desfavoráveis internacionais de pagamento (por exemplo, o aumento de diferenças cambias entre dólar e moeda local, juros elevados, entre outros), seja pela redução de arrecadação pelo fraco desempenho econômico global, o qual prejudica tanto a liquidez dos Estados quanto de empresas (UNECA, 2020, p. 14-15; ECLAC, 2020, p 3-7; IMF, 2020, p.2-6; UN, 2020).

Do ponto de vista social, o cenário pré-pandemia também não era favorável, em vista da dificuldade de manutenção a longo prazo dos avanços conquistados. Em 2015, em torno de 736 milhões de pessoas ainda viviam em extrema pobreza (WORLD BANK, 2018); em 2019, a estimativa era de que aproximadamente 1,6 bilhão de pessoas sofreriam com a debilidade de acesso a serviços básicos de saúde, educação, alimentação, segurança, bem como as discriminações em razão de gênero, cor, orientação sexual, religião, condição de migrante

insustentável a longo prazo - tanto pelo esgotamento dos recursos, quanto crescimento do compromisso global para combate às mudanças climáticas - a sua manutenção revela-se como uma armadilha, na medida em que o alto custo da mudança e ganhos financeiros a curto prazo geram dificuldades para seu abandono. 
- fatores estes que extrapolam as questões de renda (PNUD, 2019, p. 7).

A tendência é que estes números aumentem significativamente como decorrência do aprofundamento da crise econômico-financeira gerada pela pandemia, caso os países em desenvolvimento não consigam implementar medidas simultâneas de controle da epidemia, de proteção social e de crédito - não apenas para empresas transnacionais e bancos, mas especialmente para pessoas desprovidas de renda e pequenas empresas. Há a estimativa de aumento em até 29 milhões de pessoas para a linha da extrema pobreza somente na África (UNECA, 2020, p. 9).

Importante destacar que as medidas de distanciamento social e fechamento de fronteiras, em que pese indispensáveis para administração da crise sanitária, impactaram severamente os empreendimentos e emprego relacionados ao turismo (ECLAC, 2020, p.11-12; UNECA, 2020, p.19), bem como catalisaram o processo de substituição da atividade laboral presencial pela remota, com redução de postos de trabalhos convencionais, tendência que já estava em curso a partir da substituição de tecnologias digitais e robóticas (WTO, 2019, p. 5), embora o número de postos de trabalho perdidos não necessariamente serão recuperados na mesma quantidade e velocidade (OECD, 2020, p. 6).

Para além dessa perda de postos de trabalho, a ONU destaca uma maior fragilidade por parte daquelas que já estavam inseridas no contexto da economia informal, as quais serão severamente prejudicadas durante a presente crise justamente pela ausência de proteção social inerente a essa condição (UN, 2020, p.5). Neste sentido, merece atenção a armadilha da vulnerabilidade social, relacionado às pessoas que saíram da linha da pobreza nas últimas décadas, suscitada pela CEPAL (ECLAC, 2019): a redução geral da pobreza ocorrida nos últimos anos, embora benéfica, criou um novo desafio relacionado à classe média (representante de 40\% da população dos países latino-americanos e caribenhos). Esta parcela 
possui uma taxa de informalidade de emprego alta e baixa proteção social. Há igualmente pouca chance de investimento no seu próprio capital humano e no acúmulo financeiro para posterior atividade empreendedora - e, desta forma, quase nenhuma segurança financeira para enfrentamento da presente crise econômico-financeira aprofundada pela pandemia.

Além desses apontamentos, importante a consideração sobre entraves estritamente jurídicos: um dos primeiros problemas identificados é a própria exigibilidade do desenvolvimento enquanto direito, em especial pela sua estreita ligação com os direitos econômicos, sociais e culturais. Sem dúvida, a inexistência de um tratado específico, a previsão de dispositivos genéricos e esparsos sem caráter impositivo, ou de marcos regulatórios sobre o tema, são exemplos de entraves utilizados para justificar a inexigibilidade de condutas.

Neste ponto, revela-se ainda atual a reflexão de Norberto Bobbio (2004, p.46-62), o qual, já apresentando certo descrédito na evolução moral kantiana, indicava que a efetivação dos direitos humanos dependeria em grande parte da atuação do próprio Estado, ator social que detém em última análise o poder coercitivo. Assim, ao final do século XX, para além desse reconhecimento formal de direitos, a principal indagação seria em como a comunidade internacional implementaria um sistema universal de gestão de crises globais efetivo. Isso porque não se pode olvidar que há violências perpetradas pelo próprio Estado. Talvez este ainda seja um dos maiores dilemas jurídicos da ordem jurídica internacional - e, consequentemente, do direito ao desenvolvimento enquanto um direito humano fundamental.

Além disso, o sistema internacional dos Direitos Humanos, contexto no qual se insere o direito ao desenvolvimento, foi originariamente pensado a partir de uma ótica de responsabilização do Estado. Entretanto, como já exposto, o mundo globalizado é dotado de relações transnacionais com atuação de uma diversidade de atores sociais distintos do Estado. A atuação desses atores poderá igualmente 
ser contrária ao desenvolvimento. Neste ponto, questiona-se: existe alguma responsabilidade propriamente jurídica para, por exemplo, empresas transnacionais em âmbito global? Por ora, somente existe a já conhecida e limitada responsabilidade civil e administrativa em âmbito nacional.

Válida a crítica de Welber Barral (2005) no sentido de que o uso do Direito para promoção de mudanças sociais e econômicas também possui suas limitações. A depender da forma como posto, o próprio ordenamento jurídico poderá constituir um entrave. Segundo o autor, o ordenamento jurídico poderá ter características favoráveis ao desenvolvimento - como regras claras e previsíveis, tratamento equitativo aos cidadãos, participação democrática e eficiência do judiciário que, a contrário sensu, caso não estejam presentes, poderão constituir um entrave em $\mathrm{si}^{10}$ - ou desfavoráveis - como o senso

\footnotetext{
${ }^{10}$ Aqui, mencionam-se alguns exemplos do porquê a ausência das características favoráveis constituem um entrave em si: 1 - necessidade de regras claras $e$ previsíveis: um sistema confuso e com regras imprevisíveis permite a diferença entre cidadãos (aqueles que conhecem os limites e flexibilidade das regras e os que se sujeitam à sua faceta mais autoritária), a insegurança para investimentos, assim como afeta negativamente as garantias de liberdade e de confiança na estrutura social; 2 - tratamento equitativo aos cidadãos; 3 - necessidade de participação democrática, não somente na criação normativa, mas ao longo da implementação e fiscalização, com garantia de transparência e de debate democrático, a fim de reduzir a corrupção, trazer credibilidade e legitimidade, possibilitando a formulação de decisões mais coerentes com a realidade que pretendem regulamentar e facilidade do seu cumprimento voluntário; 4 - Eficiência do judiciário: a percepção de que o judiciário é ineficiente, corrupto ou tendencioso tem efeito negativo para o processo de desenvolvimento, na medida em que serve como incentivo à inadimplência, impedimento ao investimento e à efetivação de contratos, favorecendo à não resolução dos conflitos.
} 
comum dos juristas ${ }^{11}$ e uma estrutura regulatória inadequada ${ }^{12}$ (BARRAL, 2005, p.31-60).

Por fim, vale destacar que inexiste na atualidade uma estrutura regulatória específica para o direito ao desenvolvimento, o qual, a despeito de sua importância, permanece com tratamento secundário, de modo que a discussão e elaboração de um novo marco sobre o tema se torna ainda mais relevante e deverá considerar os desafios acima expostos.

11 Sobre o senso comum dos juristas enquanto entrave ao desenvolvimento, identificam-se, por sua vez, três características que geram impactos negativos, a saber: a) ignorância do processo econômico: não apenas dos efeitos macroeconômicos das normas jurídicas, mas os próprios custos decorrentes da criação de um determinado direito a parcela da população e os seus efeitos para o restante, que mesmo indiretamente será responsável por esses novos custos, seja em forma de tributos, seja pela redistribuição; b) crença exagerada no poder das normas: a concepção de que a norma, em si, será suficiente para promover a mudança, que resta frustrada, seja porque a prática social é arraigada, seja porque se trata de um fenômeno natural do mercado insuscetível de ser modificado por instrumento formal como uma lei, que gera leis ineficazes ou "leis que não pegam"; c) retórica dos direitos humanos: é uma crítica específica à defesa abstrata de direitos humanos que não guardem correspondência com a realidade, sobretudo em países mais pobres, cujo contraste entre a ordem jurídica imaginária e o cotidiano de dor e miséria de boa parte da população serve apenas para deslegitimar a crença nesta mesma ordem jurídica e, muitas vezes, permite interpretações distorcidas em favor de grupos sociais que se apropriam da ordem jurídica, em detrimento ao conjunto da sociedade (BARRAL, 2015, p.51/54).

12 Já no que toca a estrutura regulatória, o autor identifica quatro características negativas, a saber: a) custos de transação: decorrem não apenas da tradição jurídica de cada país, mas da confiança nas instituições, que diminui a necessidade de atos burocráticos e de instrumentos de fiscalização, sob pena de constituir um custo relevante e assim se tornar um impedimento ao processo de criação de riqueza; b) insegurança jurídica: decorre tanto da mudança constante de normas quanto da variação interpretativa, em razão da incoerência ou falta de estabilidade do Poder Judiciário; c) comprometimento do planejamento: é a impossibilidade de se realizar um planejamento de longo prazo, em razão da inconstância ou falta de credibilidade na ordem jurídica, de modo a aumentar o risco dos investimentos, sobretudo de longo prazo, como os investimentos em infraestrutura; d) falta de transparência e liberdade: há necessidade de mecanismos jurídicos que assegurem a fiscalização pelos cidadãos, sob pena de a estrutura burocrática criar um Estado descompromissado com os interesses da comunidade, que veja a coisa pública como objeto de pilhagem. 


\section{ENFRENTAMENTO DA COVID-19: A NECESSIDADE DE RETOMADA DO DEBATE ÉTICO A PARTIR DE INSTRUMENTOS DE AFERIÇÃO DO DESENVOLVIMENTO E DA RESPONSABILIDADE COMPARTILHADA}

Para além das questões apontadas, o direito ao desenvolvimento é dotado de um sentido ético, o qual pode ser sintetizado na seguinte pergunta: "o que gostaríamos de perseguir enquanto humanidade?". Atual, portanto, a lição de Comparato (2013, p.540-566) que, ao mirar a opção para o futuro da humanidade no século XXI, invoca o mito criacionista grego de Prometeu ${ }^{13}$ para ilustrar o seguinte dilema: apesar dos avanços tecnológicos e disponibilidade de recursos, o gênero humano permanece com dificuldade em coexistir de maneira sustentável e solidária.

Tanto é verdade que, em passado não muito distante, a humanidade vivenciou a ascensão de Estados totalitários e o fenômeno da guerra total, cujo resultado foi o descarte em massa de vidas humanas e a devastação de comunidades inteiras, no que Eric Hobsbawm (1995, p.29-61) chamou acertadamente de a "Era da Catástrofe". E agora, a humanidade passa por um dilema parecido nesta pandemia, na medida em que, a depender das respostas dadas às crises sanitárias e econômico-financeiras, poderá existir uma nova catástrofe com um custo humano elevado.

Em busca de melhores abordagens para enfrentamento da COVID-19, considerando-se tanto o aspecto sanitário quanto o risco real de uma depressão econômica a nível global, eis que surgem

\footnotetext{
${ }^{13}$ Segundo o mito, dois titãs, Epimeteu e Prometeu, ficaram encarregados da criação dos animais. O ser humano restou negligenciado durante a distribuição de habilidades às espécies e, em busca de um equilíbrio, o ser humano ganhou em Prometeu um defensor que, em desafio aos deuses do Olimpo, subtrai o "fogo divino", ou seja, o conjunto de técnicas para subsistência humana e domínio da natureza; no entanto, deixa de trazer consigo o conhecimento essencial para convivência harmônica: a arte política.
} 
algumas questões importantes: os países em desenvolvimento devem manter as medidas de distanciamento social ou necessitam retomar as atividades econômicas imediatamente? Quem deveria ser responsabilizado pela conta final das perdas econômicas e sociais no enfrentamento da pandemia?

Neste dilema atual, a preocupação central imediata, sem dúvida alguma, é com a redução de perdas humanas, o que por sua vez exige mais aportes financeiros. Neste sentido, o Banco Mundial (2020a, p.7) e o Fundo Monetário Internacional (2020, p. 8-10) por exemplo, entendem que os Estados, principalmente os desenvolvidos, deverão arcar sob aspecto econômico e financeiro. Mas, mais importante é a percepção da mensagem invocada: os Estados deverão assumir uma posição de liderança na organização e direcionamento de recursos.

Digno de nota que, países desenvolvidos afetados pelo coronavirus, como os Estados Unidos, com mais de 1 milhão de casos confirmados e que ultrapassaram 80 mil mortes (WHO, 2020), já tomaram medidas econômicas por meio do Cares Act: cerca de 2 trilhões de dólares para estímulo da economia e facilitação de crédito a médias e pequenas empresas (USDT, 2020). Mas, como ficarão países em desenvolvimento que não dispõe desses recursos?

A epidemia já se alastrou pela América Latina (quase dois milhões de casos confirmados) e está apenas começando no continente Africano (cerca de 50 mil casos confirmados), conforme estimativas oficiais (WHO, 2020). Neste sentido, vale enfatizar que a África possui 600 milhões de pessoas que vivem em áreas urbanas e 56\% (com exclusão do norte da África) vivem aglomeradas em favelas, sem condições de higienização ( $36 \%$ da população não tem acesso a lavatórios e $30 \%$ tem acesso restrito), além da grande fragilidade dos respectivos sistemas de saúde em relação aos demais países (UNECA, 2020, p.3-7).

Há grandes desafios aos estímulos coordenados pelos Estados desenvolvidos via governança global. E neste percurso somam-se os exemplos de atuações antiglobais, como a corrida por medicamentos e equipamentos médicos estimulada principalmente pela conduta 
unilateral e desordenada de alguns países (WILLSHER; HOLMES; MCKERNAN; TONDO, 2020), bem como as restrições ou proibições comerciais que dificultam a circulação de produtos essenciais ao combate da pandemia ou de primeira necessidade como alimentos, que já foram tomadas por mais de 70 países até o momento (WORLD BANK, 2020a, p.8-9;). Essas condutas prejudicam sobretudo os países em desenvolvimento. Oportuno lembrar, neste momento, que 94\% do estoque de produtos médicos e farmacológicos dos países africanos são importados (UNECA, 2020, p.4).

Assim, embora se pregue a existência de uma comunidade internacional mais unida, a humanidade encontra-se novamente em face daquele primeiro dilema ético relacionado à convivência humana sustentável e fraterna. Desta vez, espelhado na ausência de lideranças globais com capacidade para coordenar e direcionar adequadamente recursos, tecnologias e pessoas no combate ao inimigo em comum: o COVID-19 (HARARI, 2020).

Por outro lado, do ponto de vista estrutural, as relações econômicas estão sofrendo mudanças radicais neste período. O modelo de globalização baseado em redes de produção internacional, altamente dispersas geograficamente, o qual favoreceu grandes desigualdades, mostrou sua fragilidade em face de eventos não previstos e está sendo acompanhado pela restruturação e relocação de empresas em direção a uma regionalização da produção e maior proximidade para atendimento de mercados finais. Há uma preocupação mais centrada na integridade desta cadeia de fornecimento - oportunidade na qual poderá ocorrer o fortalecimento das relações regionais possivelmente mais favoráveis aos países em desenvolvimento no longo prazo (ECLAC, 2020, p.18-19).

Deste modo é que uma retomada ética se torna ainda mais necessária. Afinal, como defende Flávia Piovesan (2010), "o direito ao desenvolvimento demanda uma globalização ética e solidária”. De certa forma, trata-se de uma necessidade (ou um problema) de todos, e não apenas dos Estados. Essa concepção já era entendida por 
Cançado Trindade (1999, p. 282-283), quando na virada do século afirmou que os princípios da Declaração sobre Direito ao Desenvolvimento deveriam ser incorporados pelas instituições financeiras internacionais, e também por Kéba M'Baye (1985, p.68), ao assinalar que a garantia do direito ao desenvolvimento depende também de pessoas de direito privado ${ }^{14}$.

De fato, a ONU abarca esta linha de pensamento no enfrentamento do COVID-19, ao reconhecer que os países em desenvolvimento dependerão mais uma vez de apoio da comunidade internacional: não apenas dos bancos de desenvolvimento multilaterais, mas também de líderes do setor privado, a exemplo dos gestores de fundos de pensão, para solucionar o problema de crédito deste momento (UN, 2020, p. 14). A renegociação da dívida externa e d introdução de novos planos para auxílio financeiro direto de países desenvolvidos é retomada (UNCTAD, 2020). Dessa vez reforçada até mesmo por economistas críticos deste tipo de abordagem durante a última década, a exemplo da economista zambiana Dambisa Moyo (2020).

Mas, o que seria necessário para essa retomada ética e participação mais ativa dos demais atores sociais? Sem dúvida, o primeiro passo seria a transparência e a ampla conscientização sobre a situação atual do desenvolvimento no mundo. Neste ponto, surge uma questão técnica: a necessidade de criação de instrumentos e meios mais objetivos de aferição do desenvolvimento.

Embora se reconheça a dificuldade de quantificação em fórmulas numéricas, importante enaltecer o esforço metodológico real de se criarem critérios mais específicos a partir da elaboração de índices alternativos ao PIB (Produto Interno Bruto) e da leitura em conjunto com outros índices, possibilitando o acréscimo de elementos antes desconsiderados, como já ocorre atualmente no IDH (Índice de Desenvolvimento Humano) e no IPG (Índice de Progresso Genuíno).

14 No original: "Assurer l'exercice du droit au développement pèse aussi sur les personnes morales nationales ou internationales de droit privé". 
Direito Ao Desenvolvimento: Desafios Econômicos, Jurídicos E Éticos Nos...

Desta forma, elementos como educação, distribuição de renda (e a consideração de sua concentração de acordo com gênero, etnia, religião, entre outros) passam a ser fatores ponderáveis (BRANCO, 2012, p.268). Aliás, no começo do século XXI, o diferencial foi justamente esse: o reconhecimento sobre a necessidade da adoção de instrumentos e critérios mais específicos para aferição do desenvolvimento e a ampla divulgação de resultados, com o auxílio do estabelecimento de metas e objetivos cada vez mais concretos, incorporados pelas Metas do Milênio (ou Agenda 21), e incrementado em 2015 pela Agenda 2030 para o Desenvolvimento Sustentável.

Como segundo passo, a conscientização dos diversos atores sociais para além do Estado, e direcionamento para uma atuação coordenada e integrada, a exemplo do Pacto Global de 2000 endossado pelo então secretário-geral Kofi Annan, que estimulou a adesão voluntária das empresas transnacionais em práticas gerenciais sustentáveis. Esforço este intensificado a partir das recomendações da ONU para empresas transnacionais no enfrentamento do coronavirus: 1 - adesão às medidas de saúde, protocolos de segurança e rede de proteção social aos trabalhadores; 2 - suporte financeiro e técnico aos governos por meio do Fundo de Solidariedade de Resposta à COVID19; 3 - reorganização e planejamento dos negócios para atendimento das necessidades da presente crise (UN, 2020, p. 7).

Alguns exemplos palpáveis dessa atuação conjunta também são vistos a partir da cooperação técnica entre a comunidade científica global e empresas transnacionais, os quais não se restringem apenas à filantropia, mas também atuam para flexibilizar e facilitar relações de direito privado. Segundo De Nigri, Zucoloto, Miranda e Koeller (2020), há atualmente 50 projetos desenvolvidos em parceria por mais de 30 empresas e institutos de pesquisa supervisionados pela Organização Mundial da Saúde e, na Europa e EUA, "diversos produtores de automóveis, como Ford, Tesla, GM, Fiat, Ferrari, Jaguar, Land Rover e Rolls-Royce, negociam parcerias para 
impulsionar a produção de ventiladores mecânicos e equipamentos hospitalares".

No Brasil, afora as iniciativas de doação de equipamentos a hospitais de campanha e comunidades, há também a distribuição de kits de higiene, repasse direto de valores para hospitais públicos e instituições de saúde, mobilização de estudantes universitários para realização de testes, orientações e auxílios de grandes empresas para pequenas empresas, descontos em produtos essenciais, financiamentos a juros baixos e postergamento de cobranças, dentre outras medidas ${ }^{15}$ (REDE BRASIL, 2020).

No entanto, vale ressaltar que as tentativas de coordenação pelo Poder Público para fomento e internalização desses compromissos globais já haviam sido tomadas a partir do Plano de Ação para o período de 2017 a 2019 conduzido pela Comissão Nacional para os Objetivos de Desenvolvimento Sustentável (CNODS), criado pelo Decreto 8892/2016. que contava com auxílio técnico do Instituto de Pesquisa Econômica Aplicada (IPEA) e do Instituto Brasileiro de Geografia e Estatística (IBGE). Referida lei foi revogada recentemente por meio do decreto 10.179/2019.

Não se deve olvidar que alguns desses objetivos não são novidade para o direito brasileiro. Sayeg e Balera (2019, p. 66-76) enfatizam que a $\mathrm{CF} / 88$ foi uma das pioneiras a estabelecer a erradicação da pobreza como objetivo fundamental, de modo que o "Constituinte brasileiro de 1988, estava na vanguarda da humanidade, tendo-se antecipado à ONU quanto às Metas do Milênio de 2000; e, a Agenda 2030, adotada em 2015”. Nesta esteira, o ressurgimento de

\footnotetext{
15 Neste sentido: doação de equipamentos eletrônicos pela LG, mobilização de estudantes da UFPR para testes rápidos de COVID-19, prorrogação em até 60 dias para pagamento de parcelas de empréstimo pelo Bradesco; compra de kits de testes pela Mary Kay, parceria da Vivara com Cruz vermelha para distribuição de kits de higiene, doação de 50 mil itens de proteção individual para profissionais da saúde promovida pela AES Tietê; reparação gratuita de respiradores pela GM; doação de 750 mil unidades de álcool gel pela L'Oréal Brasil; investimento de 4,5 milhões em ações de combate ao coronavirus pela Mosaic Fertilizantes; doação de 50 milhões em alimentos e insumos médicos pela BRF; apoio técnico e consultoria da Deloitte a empresas para se adaptarem ao novo ambiente, garantia de salários aos funcionários, etc.
} 
Direito Ao Desenvolvimento: Desafios Econômicos, Jurídicos E Éticos Nos...

órgãos ou autoridades para o desenvolvimento, a exemplo das Leis Complementares n. 124/2007 (SUDAM), 125/2007 (SUDENE) e 129/ 2009 (SUDECO), poderá gerar uma indagação se, de fato, essas novas formas de articulação e integração multilaterais - ainda que incentivadas por meio de marcos regulatórios e com estabelecimento de autoridades estatais - poderiam, de fato, resultar em avanços ou apenas em novas promessas irrealizáveis para problemas de desenvolvimento estruturais.

\section{CONSIDERAÇÕES FINAIS}

Sob prismas econômico e financeiro, as circunstâncias impostas pela pandemia agravaram a situação já fragilizada de muito dos países em desenvolvimento, especialmente aqueles dependentes de exportação e turismo. A interrupção da cadeia de produção de bens e serviços, a restrição de circulação de pessoas, a queda dos preços das commodities, especialmente do petróleo, são elementos que causaram instabilidades aos mercados financeiros, reduziram as condições de liquidez de Estados e empresas, estimularam saídas de capital de seus mercados e pressionaram igualmente os mercados de câmbio, com alguns países sofrendo escassez de dólares, de modo que moedas nacionais fracas - praticamente a maior parte dos países em desenvolvimento - tiveram condições reduzidas de estímulo fiscal para estabilização de suas economias.

Há diversas armadilhas ao desenvolvimento. De todo modo, nenhuma delas poderá ser tomada como absoluta, servindo apenas como um norte para a discussão. Neste passo, uma aposta válida para superação destes entraves, para muito além da mera criação de legislação específica ou um marco regulatório sobre o tema, é o reforço 
da noção de responsabilidade compartilhada entre atores sociais por meio de compromissos globais.

Tais compromissos não são mais vistos apenas pela perspectiva financeira de cada Estado, mas de um processo de incorporação de objetivos passíveis de verificação e realização por todos os atores sociais, em prol da humanidade, e que não se restringem à filantropia, na medida em que promovem uma flexibilização e facilitação também das relações de direito privado. Exemplos concretos dessa cooperação são percebidos no enfrentamento da COVID-19, a qual poderá servir inclusive como um catalisador deste processo.

Por outro lado, não se pode ignorar que as relações transnacionais também auxiliam no distanciamento cada vez maior do centro de decisões políticas tradicionais, tomadas em âmbito nacional, das decisões de cunho econômico, o que incita a reflexão sobre a necessidade de ajustes desse modelo multilateral de gestão global, a partir do reforço de práticas mais democráticas e transparentes especialmente sobre o fluxo de capitais, tecnologias e pessoas - como forma de superação dos entraves ao desenvolvimento. A partir da constatação desta realidade é que os novos marcos regulatórios deverão necessariamente ser concebidos, sob pena de já nascerem obsoletos ou pouco efetivos.

Ainda que inexista um tratado internacional ou um marco regulatório nacional específicos sobre o tema - e que se advogue a elaboração destes - fato é que existe um compromisso global inadiável, que deverá ser reforçado sobretudo neste período de enfrentamento da COVID-19. A responsabilidade e os resultados (positivos ou negativos) não deverão recair apenas sobre os Estados, mas também sobre os demais atores sociais envolvidos.

Apesar do difícil cenário exposto, nota-se que as relações econômicas estão passando por grandes mudanças estruturais, que poderão surgir também como novas oportunidades para se repensar o modelo de produção e distribuição de bens e serviços, oportunidade em que poderá ser redimensionado o abismo entre aquelas pessoas 
Direito Ao Desenvolvimento: Desafios Econômicos, Jurídicos E Éticos Nos...

que possuem acesso e as que são alijadas do complexo processo de desenvolvimento humano.

Caso essas oportunidades sejam negligenciadas, a humanidade enfrentará um hiato na história do desenvolvimento e o custo político será demasiado caro, na medida em que contrário à essência multilateralista e universalizante preconizada pela comunidade internacional. $\mathrm{Ou}$, ao menos, esta é a expectativa gerada - o que faz muito sentido em um contexto no qual o Estado deixa de ser o protagonista exclusivo. Ao mesmo tempo em que a ética é novamente invocada, as vozes das empresas e da sociedade civil ganham bastante peso, especialmente em tempos de enfrentamento de crises globais pela humanidade, em tempos de coronavirus.

Data de Submissão: 14/04/2020

Data de Aprovação: 13/05/2020

Processo de Avaliação: double blind peer review

Editor Geral: Jailton Macena de Araújo

Editor de Área: Fernando Joaquim Ferreira Maia

Assistente Editorial: Maria Aurora Medeiros

\section{REFERÊNCIAS}

ANJOS FILHO, Robério Nunes dos. Direito ao desenvolvimento de comunidades indígenas no Brasil. Tese (Doutorado em Direito Econômico e Financeiro) - Faculdade de Direito da Universidade de São Paulo - São Paulo, 2009. 
BARRAL, Walber. Direito e desenvolvimento: um modelo de análise. In: BARRAL, Welber (org.). Direito e desenvolvimento: análise da ordem jurídica brasileira sob a ótica do desenvolvimento. São Paulo: Singular, 2005.

BOBBIO, Norberto. A era dos direitos. Tradução de Carlos Nelson Coutinho. $13^{\mathrm{a}}$ tiragem. Rio de Janeiro: Elsevier, 2004.

BONAVIDES, Paulo. Curso de Direito Constitucional. $15^{\mathrm{a}}$ ed. São Paulo: Malheiros, 2004.

BRANCO, Manuel Couret. Economia Política dos Direitos Humanos. $1^{\mathrm{a}}$ ed. Lisboa: Sílabo, 2012.

BRASIL, Deilton Ribeiro; OLIVEIRA, Leonardo Alexandre Tadeu Constant de; TRINDADE, Patrick Juliano Casagrande. Princípios do Equador e autorregulação mundial: reflexos e influências da Governança Global no Direito Interno Brasileiro. Prim Facie, João Pessoa, v. 17, n. 34, p. 01-25, 19 jul. 2018. Disponível em: https://periodicos.ufpb.br/index.php/primafacie/article/view/3889 4/20523 Acesso em: 09 mai. 2020.

COLLIER, Paul. The bottom billion: why the poorest countries are failing and what can be done about it. New York: Oxford Press, 2007.

COMPARATO, Fábio Konder. A afirmação histórica dos direitos humanos. $8^{\mathrm{a}}$ ed. São Paulo: Saraiva, 2013.

DE NIGRI, Fernanda; ZUCOLOTO, Graziela; MIRANDA, Pedro; KOELLER, Priscila. Ciência e tecnologia frente à pandemia: como a pesquisa científica e a inovação estão ajudando a combater o novo coronavírus no Brasil e no mundo. Brasília: IPEA, 2020. Disponível em: http://www.ipea.gov.br/cts/pt/central-deconteudo/artigos/artigos/182-corona. Acesso em 20 abr. 2020.

ECONOMIC COMISSION FOR LATIN AMERICA AND THE CARIBBEAN (ECLAC). Latin American Economic Outlook: development in transition, 2019. Disponível em: https://www.cepal.org/en/publications/44515-latin-americaneconomic-outlook-2019-development-transition Acesso em: 20 abr. 2020.

ECONOMIC COMISSION FOR LATIN AMERICA AND THE CARIBBEAN (ECLAC). Measuring the impact of COVID-19 with a view to reactivation. Santiago, Apr. 2020. Disponível em: https://www.cepal.org/en/publications/45477-measuring-impactcovid-19-view-reactivation Acesso em: 06 mai. 2020.

FARIA, José Eduardo. O direito na economia globalizada. $1^{\text {a }}$ ed. São Paulo: Malheiros, 2002. 
Direito Ao Desenvolvimento: Desafios Econômicos, Jurídicos E Éticos Nos...

FURTADO, Celso. O mito do desenvolvimento econômico. $2^{\mathrm{a}}$ ed. Rio de Janeiro: Paz e Terra, 1974.

HAQ, Mahbub ul. Reflections on human development. Oxford University Press, 1995.

HARARI, Yuval Noah. In the battle against coronavirus, humanity lacks leadership. Time. New York, Mar. 2020. Disponível em: https://time.com/5803225/yuval-noah-harari-coronavirushumanity-leadership/ Acesso em: 10 abr. 2020.

HELD, David; MCGREW, Anthony. Prós e contras da globalização. Tradução de Vera Ribeiro. Rio de Janeiro: Zahar, 2001.

HOBSBAWM, Eric. Era dos extremos: o breve século XX, 1914 1991. Tradução de Marcos Santarrita. $2^{\mathrm{a}}$ ed. São Paulo: Companhia das Letras, 1995.

INTERNATIONAL MONETARY FUND (IMF). Sub-saharan Africa: COVID-19: an unprecedented threat to development (Regional Economic Outlook). Washington - DC, Apr. 2020. Disponível em: http://documents.worldbank.org/curated/en/543311587659880031 /pdf/Commodity-Markets-Outlook-April-2020.pdf. Acesso em 06 mai. 2020.

M'BAYE, Kéba. Le droit au développement est-il un droit de l'homme?. In: Droits de l'homme et droit au developpement. Université Catholique de Louvain; Centre des droits de l'homme. Louvain-la-Neuve: Ed. Academia et Bruxelles: Bruylant, 1989.

MOYO, Dambisa. America and Europe should provide direct cash transfers to Africans to alleviate the covid crisis. The Economist, London, May $5^{\text {th }}$ 2020. Disponível em: https://www.economist.com/by-invitation/2020/05/05/dambisamoyo-on-a-marshall-plan-for-africa. Acesso em 11 mai. 2020.

PIOVESAN, Flávia. Direito ao desenvolvimento: desafios contemporâneos. Revista da Faculdade de Direito de São Bernardo do Campo, São Bernardo do Campo, Vol.14, n.16, 2010.

POMPEU, Gina Vidal Márcilio. Crescimento econômico e desenvolvimento humano: entre a soberania do Estado e a proteção internacional dos direitos do homem. Pensar, Fortaleza, v. 17, n. 1, p. 115-137, jan./jun. 2012. Disponível em: https://periodicos.unifor.br/rpen/article/view/228o/pdf . Acesso em: 10 abr. 2020.

REDE BRASIL: Pacto Global. Pacto contra a COVID-19. 2020. Disponível em https://www.pactoglobal.org.br/pg/pacto-contracovid-19. Acesso em: 12 abr. 2020. 
RODRIK, Dani. Goodbye Washington Consensus, hello Washington confusion? A review of the World Bank's economic growth in the 1990s: learning from a decade of reform. Journal of Economic Literature, vol. XLIV, p. 973-987, Dec. 2006.

SACHS, Ignacy. Um projeto para o Brasil: a construção do mercado nacional como motor do desenvolvimento in A grande esperança em Celso Furtado: ensaios em homenagem aos seus 80 anos. BRESSERPEREIRA, Luiz Carlos; REGO, José Marcio (orgs.). $1^{\text {a }}$ ed. São Paulo: Editora 34, 2001.

SARLET, Ingo Wolfgang.; FENSTERSEIFER, Tiago. Constituição, direitos fundamentais e proteção do meio ambiente. $4^{\mathrm{a}}$ ed. São Paulo: Revista dos Tribunais, 2014.

SAYEG, Ricardo Hasson; BALERA, Wagner. O objetivo fundamental constitucional de erradicação da pobreza. Revista de Direito Brasileira. Florianópolis, v. 22, n. 9, p. 66-76, Jan./Abr. 2019.

SEN, Amartya Kumar. Desenvolvimento como liberdade. Tradução de Laura Teixeira Motta. São Paulo: Companhia das Letras, 2013.

SILVEIRA, Vladmir de Oliveira da.; SANCHES, Samyra Haydêe Dal Farra Naspolini. Direito e desenvolvimento no Brasil do século XXI: uma análise da normatização internacional e da constituição brasileira. In: Direito e desenvolvimento no século XXI. Vladmir Oliveira da Silveira, Samyra Haydêe Dal Farra Naspolini Sanches e Monica Benetti Couto (orgs.). Brasília: IPEA; CONPEDI, 2013, p.123149.

SMITH, Adam. An inquiry into the nature and causes of the wealth of nations. Indianapolis: Liberty Classics, 1981.

STIGLITZ, Joseph Eugene. Globalization and Its Discontents Revisited: Anti-globalization in the Era of Trump. Rev. edition. United Kingdom: Penguin Books, 2017.

TRINDADE, Antonio Augusto Cançado. Tratado de direito internacional dos direitos humanos, vol. II. $1^{\text {a }}$ ed. Porto Alegre: Sergio Antonio Fabris Editor, 1999.

UNITED NATIONS (UN) general assembly resolution 41/128, Declaration on the Right to Development, 1986. Disponível em:

https://www.ohchr.org/EN/ProfessionalInterest/Pages/RightToDev elopment.aspx. Acesso em: 12 abr. 2020.

UNITED NATIONS (UN). Shared responsibility, global solidarity: responding to the socio-economic impacts of COVID-19. New York, Mar. 2020. Disponível em:

https://unsdg.un.org/sites/default/files/2020-03/SG-Report-SocioEconomic-Impact-of-Covid19.pdf Acesso em: 10 abr. 2020. 
Direito Ao Desenvolvimento: Desafios Econômicos, Jurídicos E Éticos Nos...

UNITED NATIONS CONFERENCE ON TRADE AND

DEVELOPMENT (UNCTAD). The Covid-19 Shock to Developing

Countries: Towards a "whatever it takes" programme for the two-

thirds of the world's population being left behind. Geneva, Mar.

2020. Disponível em:

https://unctad.org/en/PublicationsLibrary/gds_tdr2019_covid2_en .pdf.Acesso em 12 maio 2020.

UNITED NATIONS DEVELOPMENT PROGRAMME (UNDP). Human Development Report 2019: Beyond income, beyond averages, beyond today: inequalities in human development in the $21^{\text {st }}$ century. New York, 2019. Disponível em:

http://hdr.undp.org/en/2019-report. Acesso em: 10 abr. 2020

UNITED NATIONS ECONOMIC COMMISSION FOR AFRICA (UNECA). COVID-19 in Africa: protecting lives and economies. Addis Ababa, Apr. 2020. Disponível em:

https://www.uneca.org/sites/default/files/PublicationFiles/eca_covi d_report_en_24apr_web1.pdf. Acesso em 09 maio 2020.

UNITED STATES DEPARTMENTOFTHE TREASURY(USDT). The CARES Act Works for All Americans. Washington - DC, 2020. Disponível em: https://home.treasury.gov/policy-issues/cares. Acesso em 12 maio 2020.

WILLSHER, Kim; HOLMES, Oliver; MCKERNAN, Bethan; TONDO, Lorenzo. US hijacking mask shipments in rush for coronavirus protection. The Guardian. Apr. 2020. Disponível em:

https://www.theguardian.com/world/2020/apr/o2/global-battlecoronavirus-equipment-masks-tests. Acesso em 11. abr. 2020.

WOLKMER, Antonio Carlos; WOLKMER, Maria de Fátima Schumacher. Direitos humanos e desenvolvimento. In: BARRAL, Welber (org.). Direito e desenvolvimento: análise da ordem jurídica brasileira sob a ótica do desenvolvimento. São Paulo: Singular, 2005 .

WORLD BANK. Commodity Markets Outlook: implications of COVID-19 for commodities. Washington - DC, Apr. 2020 .

Disponível em:

http://documents.worldbank.org/curated/en/543311587659880031 /pdf/Commodity-Markets-Outlook-April-2020.pdf. Acesso em 06 mai. 2020.

WORLD BANK. Poverty and shared prosperity: piecing together the poverty puzzle. Washington - DC, 2018. Disponível em:

https://openknowledge.worldbank.org/bitstream/handle/10986/30 418/9781464813306.pdf Acesso em 10 abr. 2020.

WORLD BANK. The Economy in the Time of Covid-19 (Semiannual report of the Latin America and Caribbean region). World Bank: 
Washington - DC, Apr. 2020a. Disponível em:

<https://openknowledge.worldbank.org/bitstream/handle/10986/3 3555/9781464815706. pdf? sequence $=5$ \&isAllowed $=\mathrm{y}>$. Acesso em 08 mai. 2020.

WORLD HEALTH ORGANIZATION (WHO). WHO Coronavirus Disease (COVID-19) Dashboard. Geneva, may 2020. Disponível em: https://covid19.who.int/. Acesso em 12 mai. 2020.

WORLD TRADE ORGANIZATION (WTO). World trade report: the future of services trade, Geneva, 2019. Disponível em:

https://www.wto.org/english/res_e/booksp_e/oo_wtr19_e.pdf.

Acesso em: $10 \mathrm{abr} .2020$. 


\title{
Right To Development: Economic, Legal And Ethical Challenges In Coronavirus Times (Covid-19)
}

\author{
Daniel Jacomelli Hudler
}

\author{
Marcelo Benacchio
}

\begin{abstract}
The objective is to understand the economic, legal and ethical challenges faced by the right to develop in the scenario of the global crises triggered by the new coronavirus pandemic (COVID-19). This article applies the hypothetical-deductive method, together with bibliographic research. The first part focus at identifying the lines of economic thoughts incorporated into the legal discourse at the end of the 2oth century (neoliberal, sustainable and human) and its framework as a fundamental human right in the context of a global economy information society; the second part aims at describing economic and legal challenges for developing countries and the deepening of the economic and financial crisis; the third part presents ethical reflections on the relationship between States and the integration of other social actors in tackling the pandemic. It is possible to conclude that the international community, despite the difficulties, is moving towards an understanding of the State, the company and the civil society as co-participants in the development process, based on multilaterality and shared responsibility, together with the use of more precise instruments to measure development, internalization of these commitments based on common efforts, as well as the importance of this reality as a precondition for the creation of new regulatory frameworks.
\end{abstract}

Keywords: Right to development. Human and sustainable development. Human rights. Transnational companies. Coronavirus (COVID-19).

DOI: https://doi.org/10.22478/ufpb.1678-2593.2020v19n42.51843

Conteúdo sob licença Creative Commons: Attribuition-NonCommercial-NoDerivative 4.o International (CC BY-NC-ND 4.0) 